\title{
Tandem bike design for apartment residents as an idea to reduce air pollution
}

\author{
Bambang Iskandriawan ${ }^{1}$, Jatmiko $^{2}$, Eri Naharani Ustazah $^{1}$ and Firman Hawari ${ }^{3}$ \\ ${ }^{1}$ Department of Industrial Design, Faculty of Civil Engineering and Planning, Institut Teknologi Sepuluh Nopember, Indonesia \\ ${ }^{2}$ Department of Interior Architecture, Faculty of Technology and Design, Universitas Ciputra, Indonesia \\ ${ }^{3}$ Department of Interior Design, Faculty of Civil Engineering and Planning, Institut Teknologi Sepuluh Nopember, Indonesia
}

\begin{abstract}
Vertical housing is recently popular in urban areas since the availability of land is very limited. A strong preference for living in the city is mainly due to the home to work travel that is relatively close for those who work in the city. While residing in the vertical housing (i.e. apartment) can be an advantage, several accommodation facilities are often provided at their minimum standards. As such, a special design of bicycle for apartment residents may an effective solution. Multi-function bike, ridden either by one or two riders and its aesthetic part of interior element can be an attractive offer. Identification of marketing objectives and observation of comparable products were a crucial step in the initial process of tandem bike design. The use of bicycle in urban areas can overcome a number of motorized vehicles operating wherever the using of them may create issues such as traffic jam and air pollution. This study aims to adjust the tandem bike which can be produced commercially for the apartment residents. Stated in the research problems, the design process was successfully fulfilled. Fabrication and product testing were positively completed. A concise and comfortable bike to carry from the lobby to the apartment unit, or vice versa, was successfully created.
\end{abstract}

\section{Introduction}

In 2012, around 134 million of new middle class society grew in Indonesia, five times larger than Malaysian population and twenty five times larger than Singaporean citizens [1]. More than $50 \%$ of this number lives in urban areas. This factor causes a very high population density in the city and makes the house prices more expensive. Vertical housing (i.e. apartment) offers an affordable accommodation for those working in urban areas. Several years ago, living in an apartment was viewed as an elegant lifestyle. Nowadays, however residing in an apartment is a common lifestyle for any class of society.

As the size of an apartment unit is normally undersized (Figure 1), household furnishings and electronic equipment have to be smallest dimension as well. The selection of air conditioning type for apartment model, for example, has to fulfil the criteria of the most cost-effective type [2]. It could be concluded, which one the variant of furniture arrangement along with the best working based on the value of Cooling Coefficient of Performance $\left(\mathrm{COP}_{\mathrm{c}}\right)$ [3]. In addition, the use of bicycle around the city is becoming more popular since the government allows cyclists to ride in the main streets on car-free days. This trend encourages apartment residents to use bike. Unfortunately, the design of the bike is often problematic in such a vertical housing. Thus, a special design of the bike is required to be able to adapt to the characteristics of apartment units. The bike features needed include its function, used both as a tandem bike and as a single bike; its efficiency, a bike use depends on rider's needs; and its dimension, consuming less space in a room when not used. Such considerations are beneficial for apartment residents [4] (Figure 2).

Careful attention to notable ideas in the phases of design process results in a successful design [5]. Correlation amongst bicycle design, material, and art was investigated comprehensively by Ashby [6]. An updated analysis of bike based on either functions or conceptions is discussed comprehensively in the literature [7 and 8]. Bike design must fulfil the ergonomic rules [9, 10 and 11] directly from working trials to the finished products. The correlation amongst seat-tube angle, pedalling efficiency, and the main function of bike is crucial [12]. Construction efficacy aspect is considered to be significant aspect on designing a bike [13].

The principal question of this research is how to create tandem bike design especially for the apartment residents in flexible and efficient concepts, as well as safe and appealing to urban society. The increasing use of tandem bike is able to reduce the number of vehicles used by apartment occupants expectantly; therefore the amount of air pollution in the apartment area can also be minimized. 


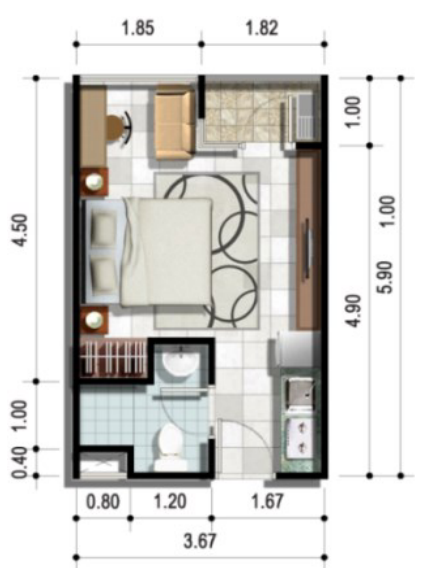

(a)

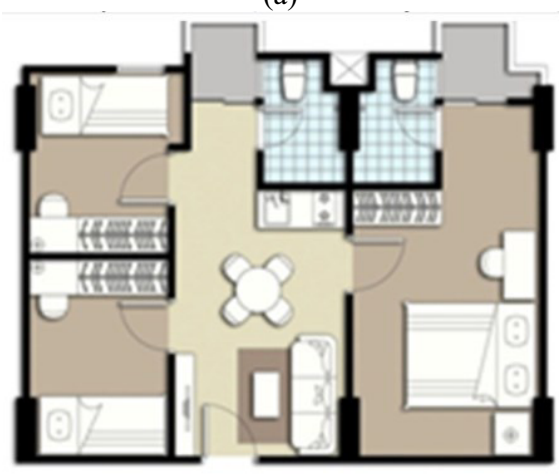

(b)

Fig. 1. An illustration of an apartment unit plan which has limited dimension: studio (a) and 3 (three) bed room type (b).

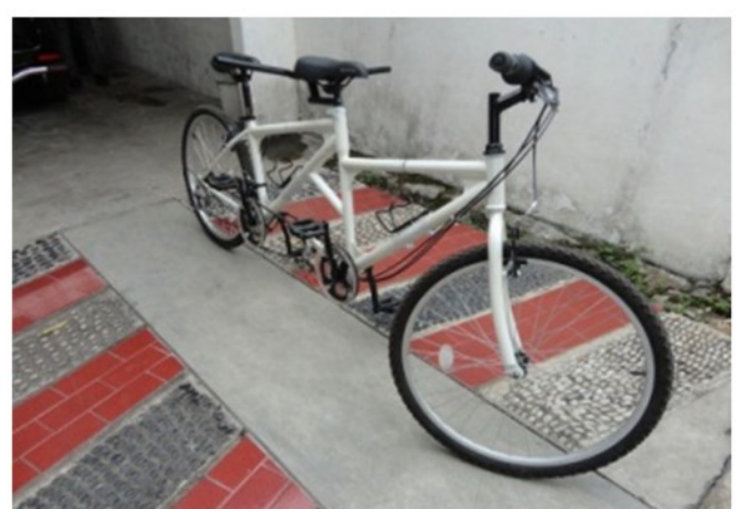

(a)

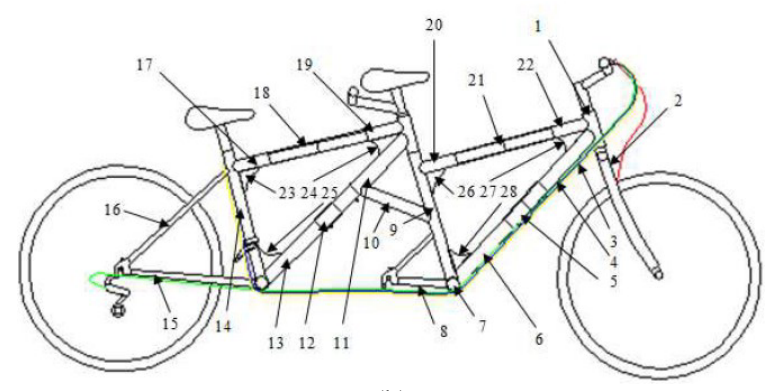

(b)

Fig. 2. Tandem bike prototype on ITS LPPM Competency Research Program (a, 2011), while still in patent process (number: P.00201200855) [3] and the technical drawing (b).

\section{Method}

The prototype development of multi-function tandem bicycle for apartment residents is well-programmed. Its development in this study is explained in the flow chart below (Figure 3.)

It is very often that problem/sub-problems/subsolutions/solution has symmetrical relationships [4]. If there is a possibility, the result of the development process will give feedback to the prior development process.

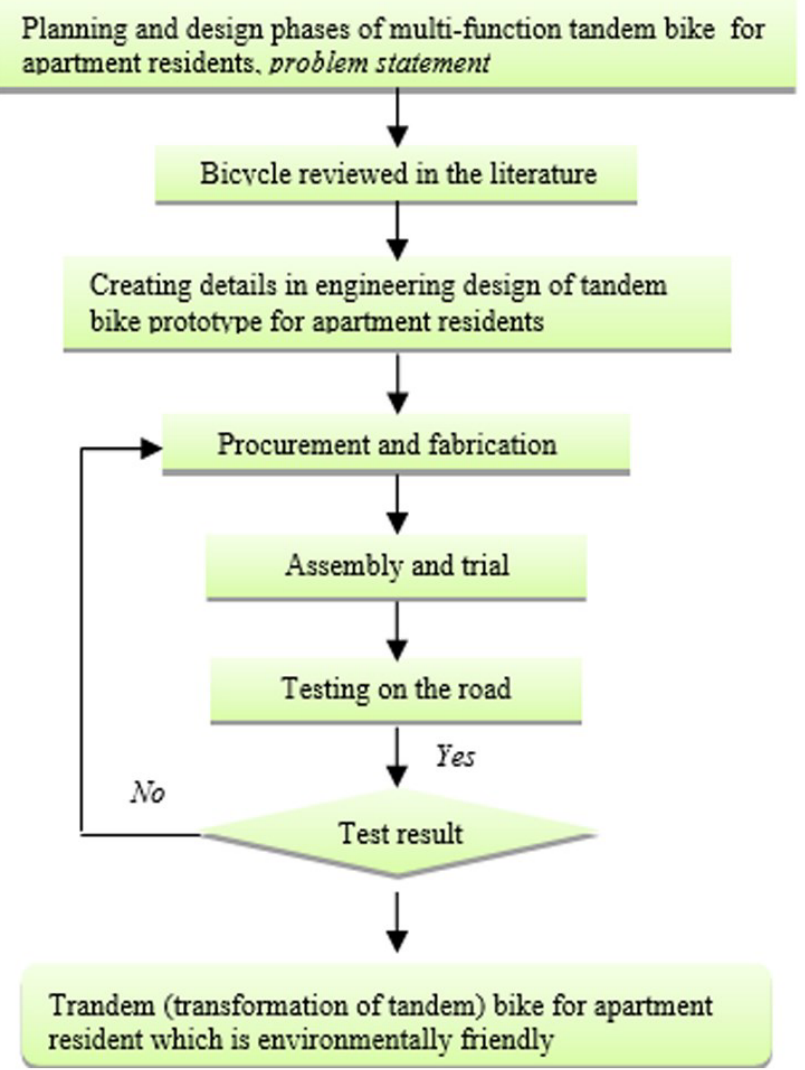

Fig. 3. Flow chart of the development of tandem bike design for apartment residents.

\section{Results and discussion}

In this study, the researchers who engaged in interior design disciplines focused more on designing and exploring the uniqueness of the apartment, while other researchers who majored in product design discipline conducted the tandem bike design. The results of analysis in this development process are compiled and discussed concurrently in the following part of this paper.

\section{Identification of the marketing objectives}

The identification of product users including the product environment where this product will be used should be clearly identified (Figure 4). The planning situation where the product will be stored can be seen in Figure 1. To be in line with the title of this study, the marketing objectives of the product users are the apartment residents, mainly the single and young couple. 
PRODUCT

Trandem
The important
dissent which come
to be the major
benefit of the
"Trandem" bike is
its capability which
is able to be
modified from
single bike into
tandem bike.
Trandem means
transform of
tandem.

\section{ENVIRONMENT}

\section{Apartment}

The marketing objectives of the apartment residents are referred to:

1. Occupants of the studio type. Trandem provides the individual needs, yet it is still possible as the way of interactions or socialization.

2. Occupants of bedroom 1 type commonly inhabited by young couples. The existence of trandem is suitable to increase togetherness.
Fig. 4. Product identification and the target of trandem market segmentation. The meaning of "Trandem" is the transform of tandem.

\section{Observation of the product settings}

Commonly, there are 2 (two) kinds of bicycle parking area in the apartment (i.e. in Figure 5); outdoor area and (semi) indoor area. Both kinds of parking area have several advantages and disadvantages. Below is the illustration of the kinds of the parking areas

\section{Itinerary of tandem bike from parking area to the apartment unit}

The route of tandem bike starting from parking area to its placement inside the apartment unit can be seen in Figure 6 (illustration 1 to 6 ). For each location, it needs several instructions concerning the unique condition of all areas mentioned.

\section{Product storage techniques in an apartment unit}

Alternative positions of tandem bicycle placement for storage techniques can be seen in Figure 7. Based on the result of apartment location analysis, as well as the problem statements, the idea schemes can be developed as can be seen in Table 1 .

\section{Designing process}

Designing process phase of tandem bike for apartment residents produced several sketch ideas, including the 3D technical drawing as can be seen in Figures 8 to Figure 12.

It is crucial to create initial idea by producing several sketches of bike. Through brainstorming amongst the team members, bicycle designs were selected from the most excellent sketches related to both single and tandem bike model for apartment residents. The main ideas of selection process were whether the design could work comfortably and whether there is a possibility to develop other bicycle frame designs for future studies.
Outdoor parking area
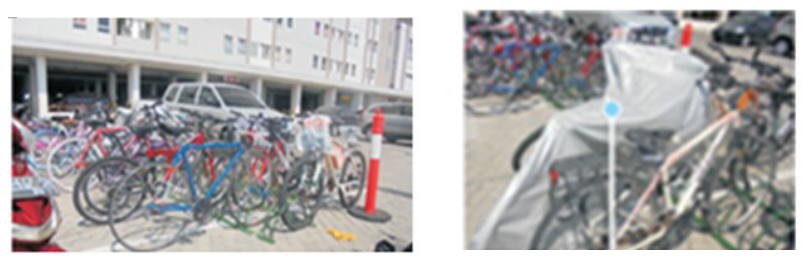

It provides bike racks for security reason. Also, it serves appropriate spaces to organize and to make it tidy. To protect the bike from hot weather and raining, the users use bike cover.

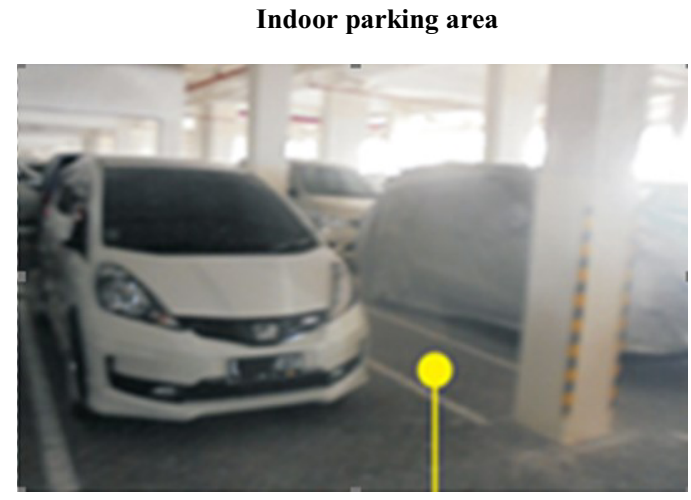

This kind of parking area provides spaces for two-wheel vehicle, motorcycle and bicycle. However, this facility commonly limits the vehicle numbers; one car and one motorcycle spaces parking area for one resident of the apartment unit.

Fig. 5. Bicycle parking area in the apartment; (semi) outdoor and indoor.

After determining its functions, bike component design which was easy to operate and uncomplicated fabrication was taken into account. To fulfil the process of fabrication and assembly, it needed detailed engineering design from technical drawing. 3D drawings were eminent to validate the works of skilled labourers since it provided closer to the representativeness of specific object than technical drawing. In addition, 3D drawings could visualize how the bike was mounted on the wall as one of possibilities to store the bike in an apartment unit (Figure 12).

\section{Fabrication process and components assembly}

Fabrication and assembly process phase (Figure 13) constitute to complicated process and as a matter of fact, the choice of the process is decided by employing trial and error approach. In the sketch process, technical or operational drawing can be imagined, yet in the process of execution, some difficulties can be found during fabrication.

One of the significant findings in this study is the tandem bike can be transformed into trolley. By transforming into trolley, the bike could be carried from the lobby to apartment unit or vice versa uncomplicatedly. Figure 14 shows the model of it. The bike is possible changed to another function such as a table when it is not to be used as the bike (Figure 15). 


\section{From parking area to the lobby}

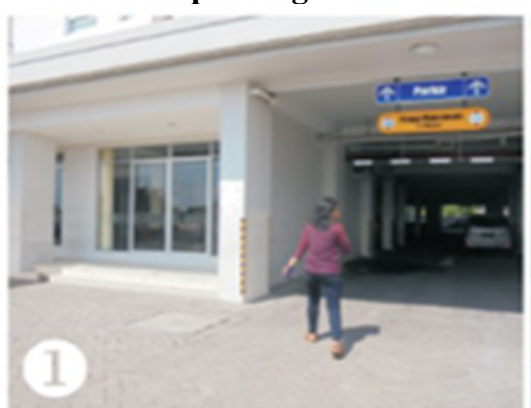

From parking area to the apartment building, the bike can be ridden.

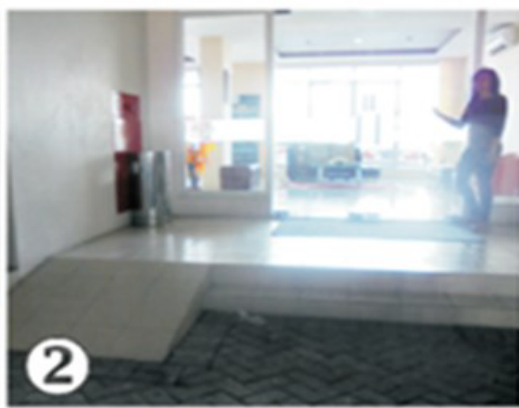

At the front of the lobby, the bike must be folded and then put in the bag entirely or some parts with the remains are carried.

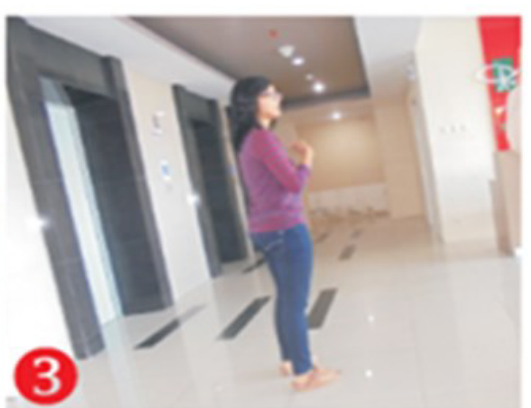

To keep the lobby clean, the bike has to be packaged in the bag, then pulled like a trolley, or brought like a backpack, when the biker is ready to enter the elevator in the lobby.

\section{From the lobby to the apartment unit}

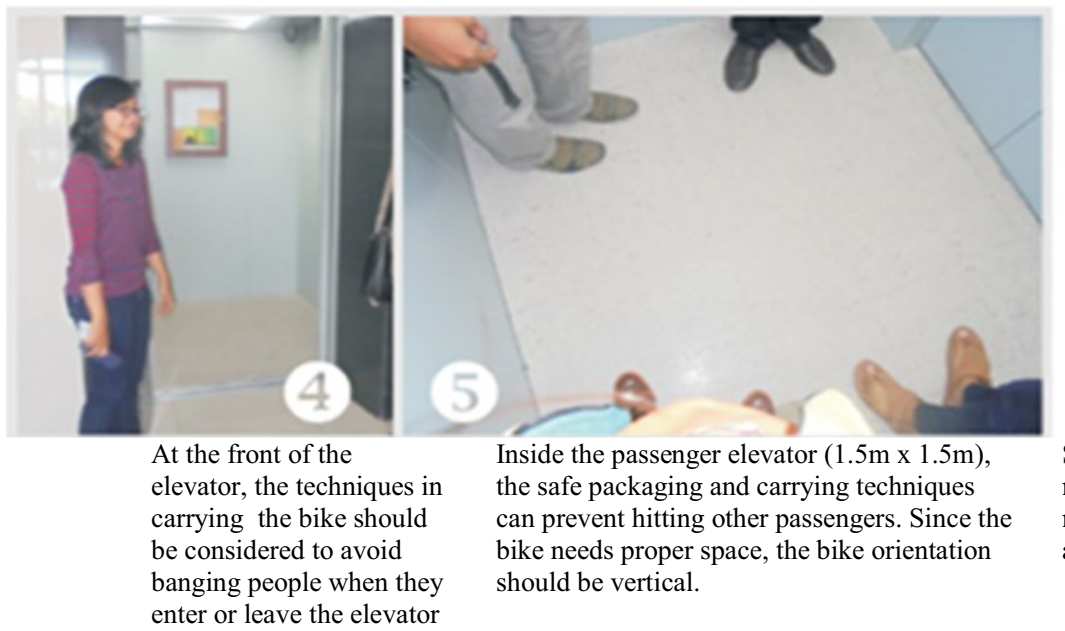

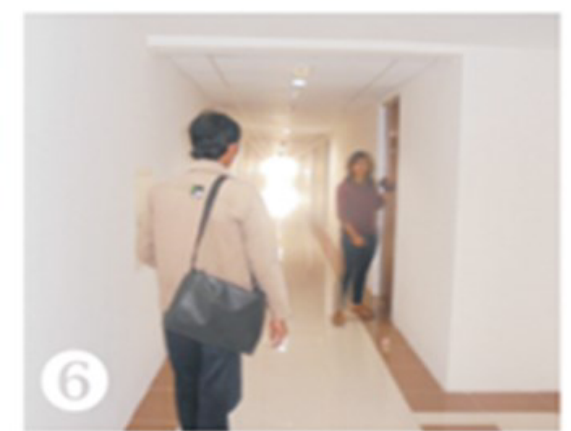

Since the corridor of the apartment must be clean from any object, the bike must be stored or parked inside the apartment unit.

Fig. 6. Tandem bike carrying scenarios in the apartment ( $1^{\text {st }}$ to $6^{\text {th }}$ steps $)$.

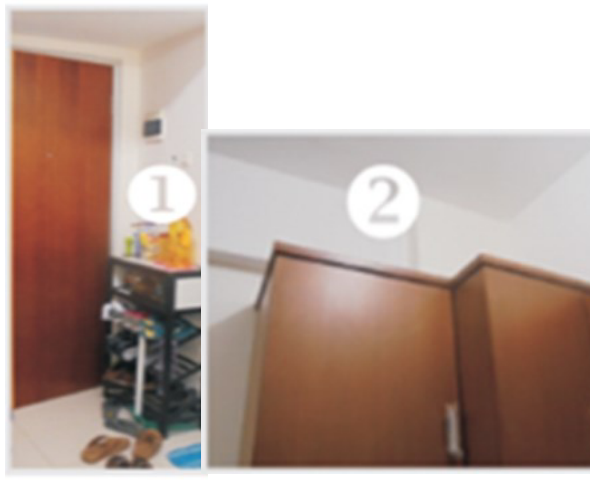
main door. It is vertically stored above the shoes rack.

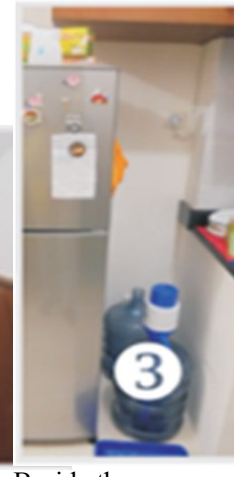

Beside the refrigerator. The gap between the wall and the refrigerator can serve as the bike protector.

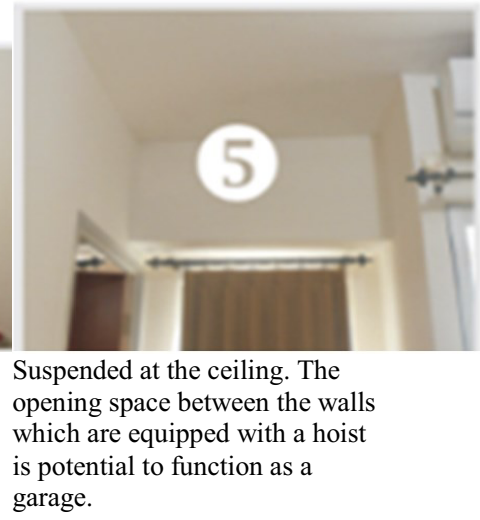

Wall mounted. The bike attached to the wall space in the living room possibly becomes an interior decoration.

Fig. 7. The possible storage techniques for tandem bike in an apartment unit (1 to 5). 
Table 1 Ideas scheme (concept)

\begin{tabular}{l|l}
\multicolumn{1}{c|}{ Parking method } & \multicolumn{1}{c}{ Additional frame function } \\
$\begin{array}{l}\text { All bike parts parked at the } \\
\text { basement }\end{array}$ & $\begin{array}{l}\text { They are only as the component } \\
\text { (part) }\end{array}$ \\
\hline $\begin{array}{l}\text { All bike parts are carried and } \\
\text { stored in an apartment unit }\end{array}$ & $\begin{array}{l}\text { They are functioned as the support } \\
\text { for the bike (part) }\end{array}$ \\
\hline $\begin{array}{l}\text { Some bike parts parked at } \\
\text { the basement and the } \\
\text { remains stored in the } \\
\text { apartment unit }\end{array}$ & $\begin{array}{l}\text { They are functioned as a tool which } \\
\text { is useful for user activities, i.e. table, } \\
\text { partition, container, and hanger. }\end{array}$ \\
\hline
\end{tabular}

(a)

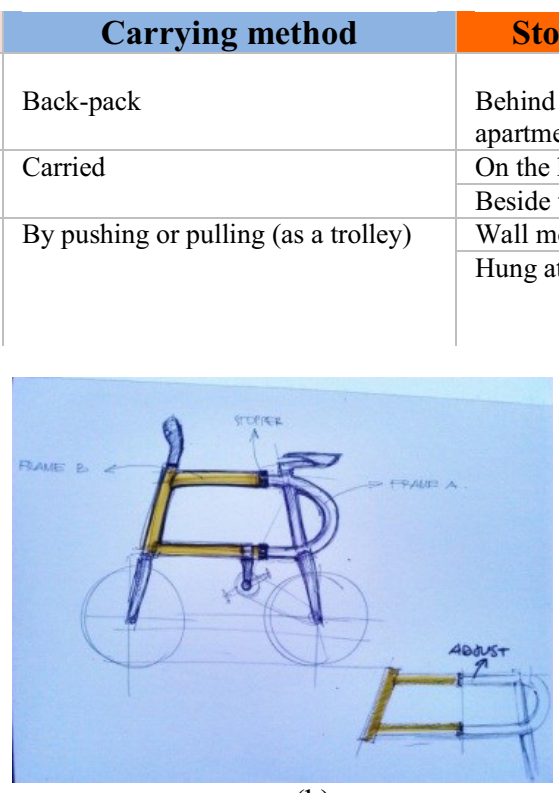

(b)

Fig. 8. Tandem bicycle sketches for the apartment residents as a tandem (a) and as a single bike (b).
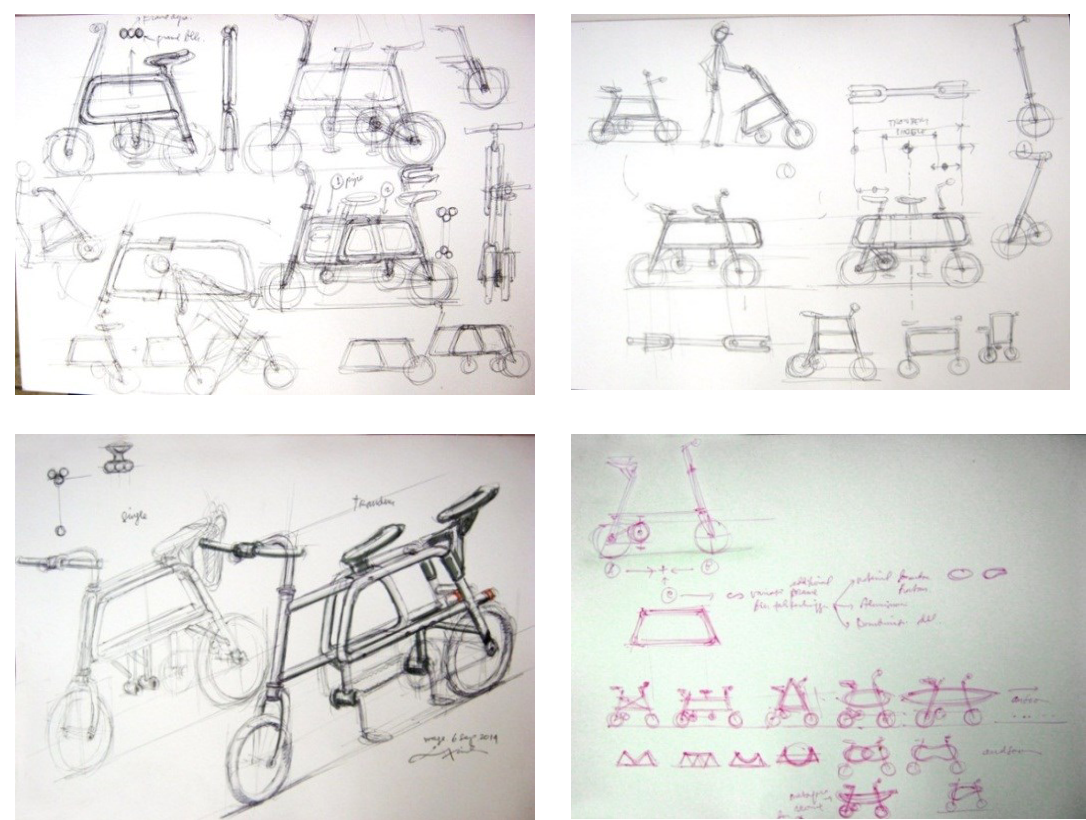

Fig. 9. Tandem bike sketches for apartment residents, made to optimize and simplify the operation and to accomplish the design purpose.
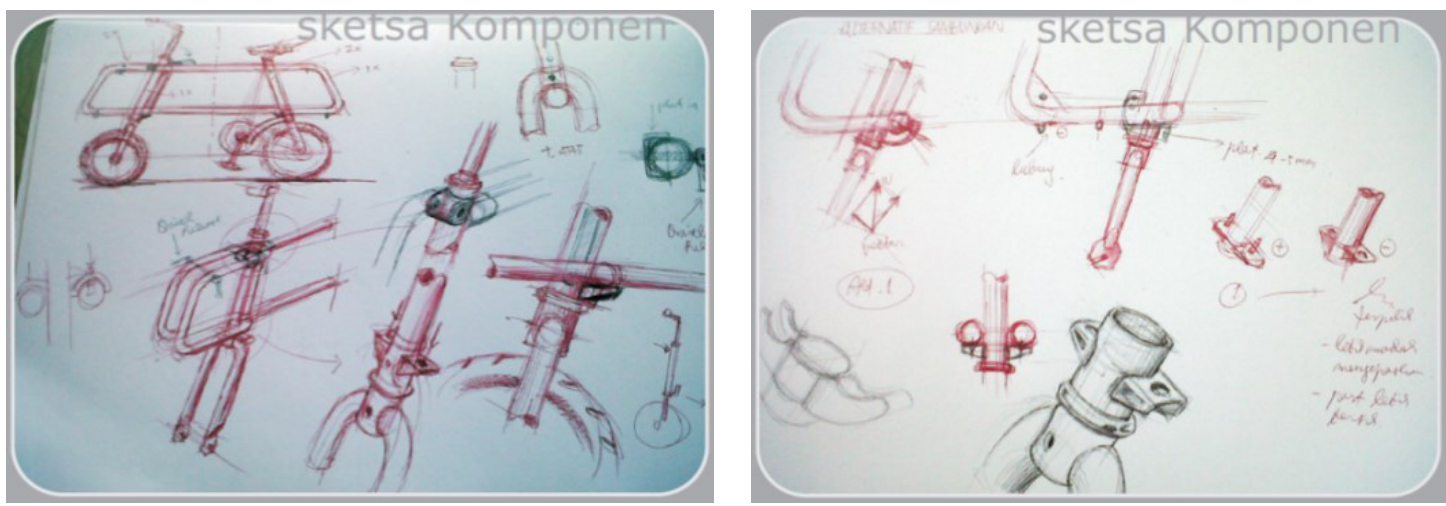

Fig. 10. Tandem bike component sketches for apartment residents, made to obtain simple operation and fabrication. 


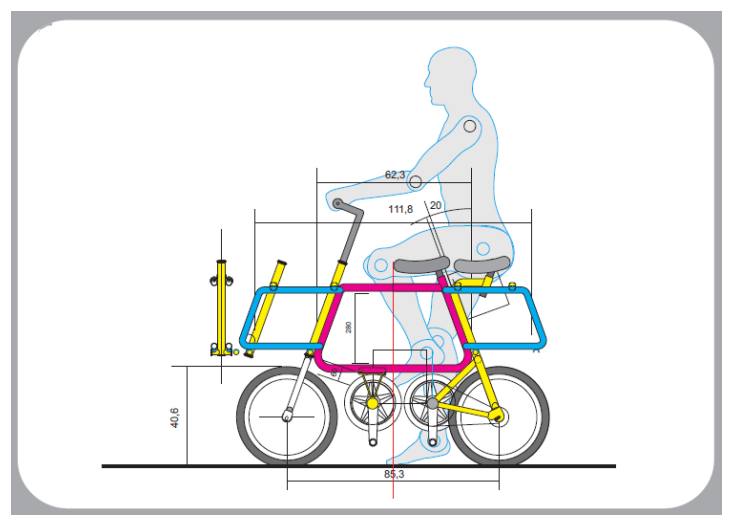

(a)

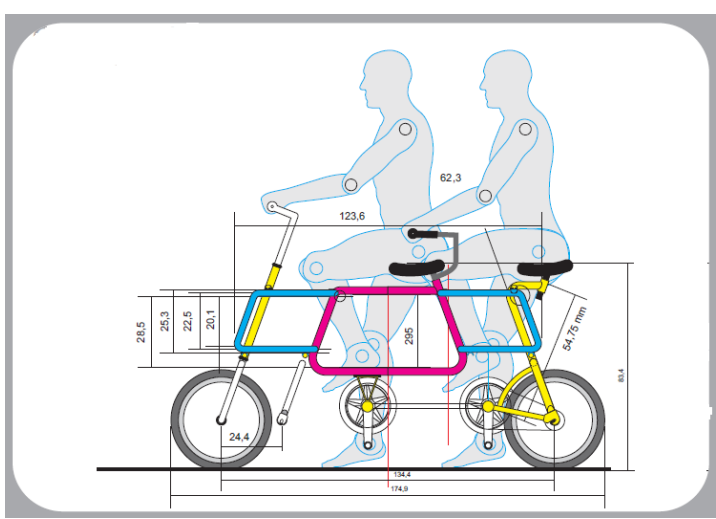

(b)

Fig. 11. Tandem bike technical drawing results for apartment residents: as a single bike (a) and as tandem bike (b).

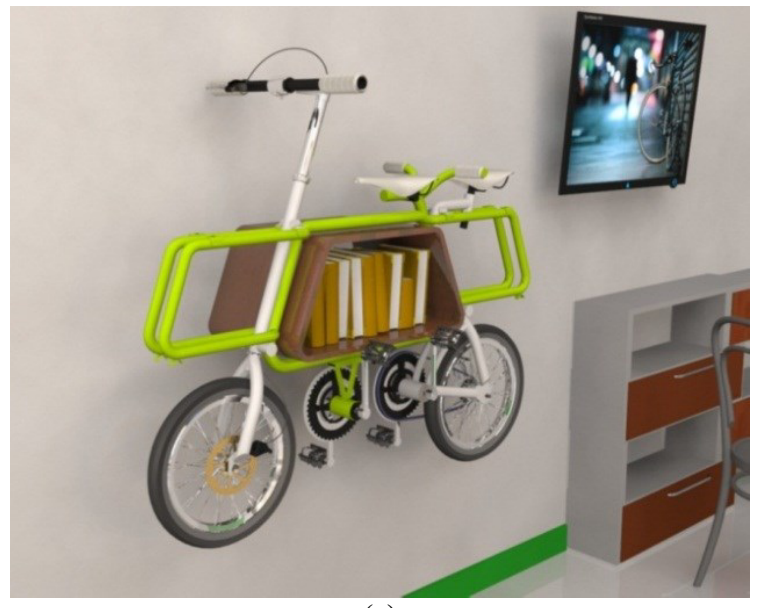

(a)

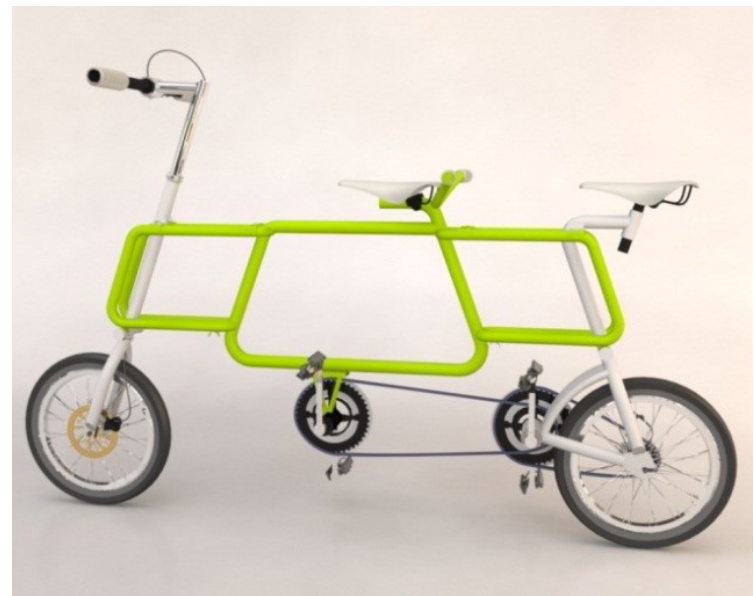

(b)

Fig. 12. Placement alternatives results of tandem bike in a single bike form as the book shelf in apartment unit (a), and the bike form which is ready to be used as a tandem bike (b).
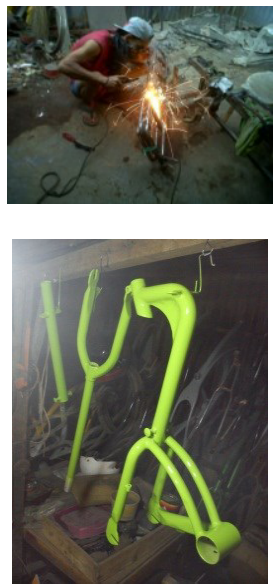
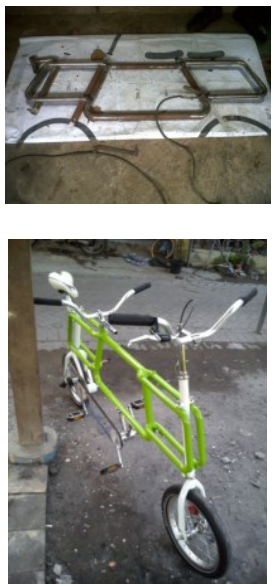
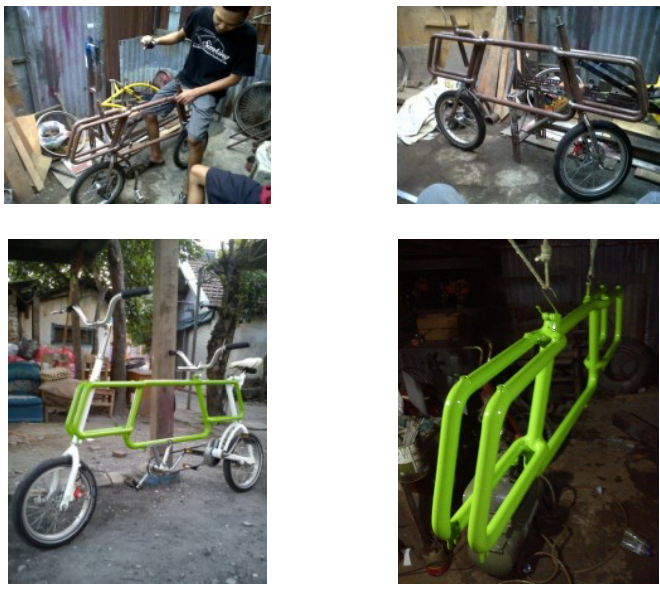

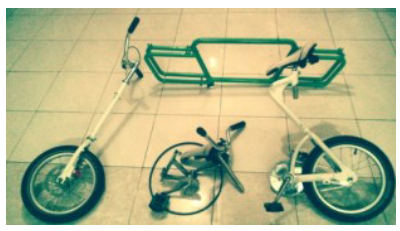

Fig. 13. Fabrication and components assembly process results of tandem bike for the apartment residents. 


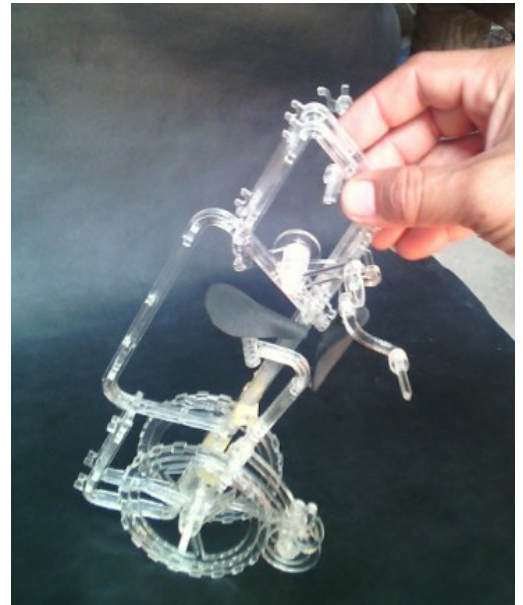

Fig. 14. Carrying method study result of bike from parking area to the lobby and to the apartment unit as a trolley.

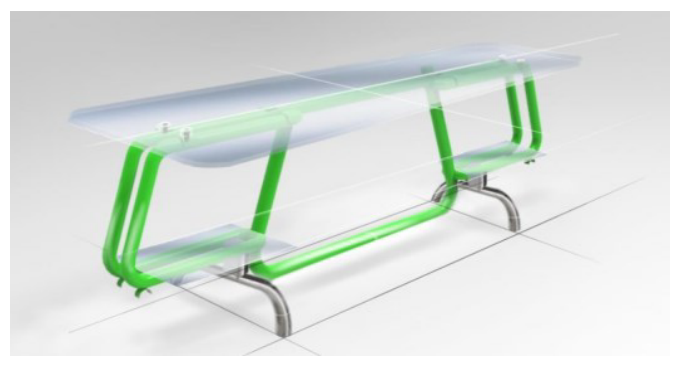

Fig. 15. Another function study result of the apartment bike: table.

\section{Conclusions}

Currently, there is a possibility to construct tandem bike prototype for apartment residents. Although the present research has produced some findings, there are some other related areas that need to be investigated to improve both the design and the function of tandem bike in the future research.

The purpose of this research is to enrich the design process theory in which it is viewed as specific tools that are likely to be used by designers. However, those specific tools can be altered on the users' purpose.

Since the fabrication process of tandem bike was created manually, the bike dimension was not perfectly shaped. The main frame, for instance, was dissimilar. In the future manufacturing process, however, it can be improved.

Concerning the test results, the tandem bike was strong enough to support two adult people at the time it was used. This try-out was also conducted on the bumpy road to examine the strength of the fork and the main frame.
By using tandem bike, the quality of social life around the apartment can be increased. Unlike the car users, the bike users are most likely to be able to interact with others comfortably. Furthermore, the escalating number of cyclists possibly reduces the number of vehicle driven by apartment occupants. More importantly, pollution around the apartment can be lessened.

The researchers are aware that the present study has some limitations. Therefore, further research on more innovative and precise tandem bike for apartment residents is required.

This work was supported by the Ministry of Higher Education, Research, and Technology, Republic of Indonesia.

\section{References}

1. Apartment Guide, Edition 01/I/July 2012, (Publisher: Kompas Gramedia, 2012)

2. B. Iskandriawan, IJAER 9, 19, 6277-6290 (2014)

3. B. Iskandriawan, ARPN JEAS 11, 2, 851-856 (2016)

4. B. Iskandriawan and Jatmiko, AMM 607, 920-925 (2014)

5. N. Cross, Engineering Design Methods, Strategies for Product Design, Second Edition (John Wiley \& Sons Ltd, Baffins Lane, Chichester, West Sussex, PO19, England, 1998)

6. M. Ashby, K. Johnson, Materials and Design, The Art and Science of Material Selection in Product Design (Butterworth Heinemann, Oxford, UK, 2007)

7. M. Embacher, Foreword by Paul Smith, Cyclepedia A Tour of Iconic Bicycle Designs (Thames \& Hudson, ISBN 978-0-500-51558-7, 2011)

8. D. Wiyancoko, Desain Sepeda Indonesia (KPG (Kepustakaan Populer Gramedia) Jakarta, ISBN: 978-979-91-0243-0, 2010)

9. E. Grandjean, Fitting the Task to The Man: An Ergonomics Approach (Philadelphia: Taylor \& Francis, 1986)

10. H. Christians and A. Bremmer, Applied Ergonomics, 29, 3, 201-211 (1998)

11. PC Donkers, HM Toussaint, JF Molenbroek and LP Steenbekkers, Applied Ergonomics, 24, 2, 109-118 (1993)

12. C.Hsiang Chen, Y. Hao Huang and T. Yuang Shiang, J. Science and Cycling, 4, 1, 28-32 (2015)

13. R.L. Mott, Machine Element in Equipment Design, Volume 1 and 2 (Publisher: Andi, 2009) 